\title{
DEVELOPMENT OF WEB-BASED EXAMINATION SYSTEM USING OPEN SOURCE PROGRAMMING MODEL
}

\author{
Olalere A. ABASS \\ Dept. of Computer Science \\ School of Science \\ Tai Solarin College of Education \\ Omu-Ijebu, Ogun State, Nigeria \\ Samuel A. OLAJIDE \\ Dept. of Educational Technology \\ Faculty of Education \\ University of Ilorin, Ilorin, Nigeria \\ Babafemi O. SAMUEL \\ Dept. Computer Science \\ School of Science \\ Tai Solarin College of Education \\ Omu-Ijebu, Ogun State, Nigeria
}

\section{ABSTRACT}

The traditional method of assessment (examination) is often characterized by examination questions leakages, human errors during marking of scripts and recording of scores. The technological advancement in the field of computer science has necessitated the need for computer usage in majorly all areas of human life and endeavors, education sector not excluded. This work, Web-based Examination System (WES) was, therefore, born out of the will to stymie the problems plaguing the conventional (paper-based) examination system by providing a campus-wide service for e-assessment devoid of irregularities and generally fair to examinees and equally enhances instant feedback. This system developed using combination of CSS, HTML, PHP SQL MySQL and Dreamweaver is capable of reducing proportion of workload on examination, grading and reviewing on the part of examiners. Thus, the system enables the release of examination results in record time and without error. WES can serve as an effective solution for mass education evaluation and offers many novel features that cannot be implemented in paper-based systems, such as real time data collection, management and analysis, distributed and interactive assessment towards promoting distance education.

Keywords: Web-based examination system, e-examination, computer-based test.

\section{INTRODUCTION}

The explosive growth of the Internet is making available radical new means of communication that affect life in diverse areas as business, entertainment and education. While older methods of accomplishing tasks continue to be used, the Internet offers unique advantages (Rahneva, 2004). One important area of application of the web technology is in the development of web-based testing and assessment (Iyilade \& Adekunle, 2005). Before the massive influx of Information Technology (IT), students's academic performances were evaluated via paper-based system of assignments and tests. Since recent progress in state-of-the-art IT has advanced significantly, educational products are now available electronically (including the web technologies) and new methods of educational assessment have emerged. 
The World Wide Web (WWW) has gained popularity within educational sector and become an inexpensive, easily accessible way to communicate, disseminate information, teach and examine courses and conduct researches. Consequently, there exists wide preference and adoption of web-based testing and assessment over the traditional paperbased method of assessment which has over decades been characterized by examination questions leakages, human errors during the marking and recording of scores. Web-based testing and assessment systems offer greater flexibility than the traditional approach because test could be offered at different times by students and in different locations (Akanbi \& Adetunji, 2012). e-Examination system rides on the huge success of Information and Communication Technology (ICT) and its various features, security, reliability and consistency. The system simplifies the examination process by computeraided control and automatic marking to reduce the complex paper work (Meng \& Lu, 2011).

In this current adoption of ICT towards promoting distance education where distance between leaners and instructors is no longer a barrier, Web-based Examination System (WES) is an effective solution for mass education evaluation. The system is based on a Browser/Server framework which carries out the examination and auto-grading for objective questions. The system facilitates conducting examinations, collection of answers, auto marking the submissions and production of reports for the test. It will be used via Internet and is therefore suitable for both local and remote examination.

The system developed reduces the large proportion of workload on examination, grading and reviewing. It also has the potentials to reduce drastically examination malpractice as examinees are duly authenticated online in a real-time manner and their results are released some few minutes after the completion of the examination because where the lecturer would spend weeks marking scripts and grading manually, the computer would grade the students as soon as they finish their paper, get their already stored continuous assessment and produce their eventual result. It also enhances effective distance education as examinees can write examination in any part of the world and equally get their results instantly.

The remaining parts of the paper is organized as follows. Section 2 reviewed the related literatures. In Section 3, methodology and system design techniques are highlighted. The Section 4 focuses on the implementation of the design while Section 5 presents the conclusion and recommendations.

\section{REVIEW OF RELATED LITERATURE}

\section{Traditional versus Electronic Tests}

In educational institutions, tests are conducted to evaluate the academic progress of learners; review, compare and measure the effectiveness of methods of instruction; serve as basis of guidance and counselling to students, selection for prize award and employment and grading for the purpose of certification.

In the context of education system, one possible purpose of a test is to assess whether a learner has attained an educational goal. The outcome of such a test can help instructors analyze problems with his method(s) of instruction and to better understand the learner's strengths and weaknesses in a given subject. Test can be used to fine-tune the instruction environment or method based on the analytical results to improve the instructor's teaching performance (Chen, et. al., 2005). There are currently two methods for conducting tests: (i) The traditional method of using paper and pencil tests, including the creation of test items, the grading of students' test sheets, and the analysis of learner's responses for each test item, which is considered to be tedious; and (ii) Computer-Based Tests, an electronic examination, allows test activities to be carried out using different electronic platform/environment. Basically, the electronic examination (eExamination) system involves the conduction of examinations using various electronic 
devices (mobile phones, computers etc) connected to the testing system via the Internet or the Intranet. The process is predominantly automated, which means the administration, grading, reviewing of the examination is of little effort. Usually the examination is in form of multiple-choice test.

Ayo, et. al. (2007) defines e-examination as a system that involves the conduct of examinations through the web or the intranet. They proposed a model for e-Examination in Nigeria where all applicants are subjected to online entrance examination as a way of curbing the irregularities as proposed by the Joint Admissions Matriculation Board (JAMB), a body saddled with the responsibility of conducting entrance examinations into all the Nigerian universities. This model was designed and tested in Covenant University, one of the private universities in Nigeria. Their findings revealed that the system has the potentials to eliminate some of the problems that are associated with the traditional methods of examination such as impersonation and other forms of examination malpractices.

Gardner, et. al. (2002) in their work developed a computer-supported learning system, named CECIL, which included an interesting function of 'self-Assessment' to enhance students' learning effectiveness. The function of 'self-assessment' is equipped with item pools and teachers can administer and construct examinations easily through the Internet. They also pointed out that the advantages of item pools are that 'teachers are able to incorporate large item banks (item pools) from textbook publishers and batch load these questions with a minimum of manual effort'. Moreover, Gardner et al. (2002) also stated that teachers who administer and construct an examination through the Internet have the advantage of helping students to check their understanding of the learning materials at all hours.

Wang et al. (2004) in their work developed an assessment system using Triple-A Model (assembling, administering, and appraising) as the baseline qualification in order to provide the most comprehensive form of Computer-Based Test (CBT) or Web-Based Test (WBT) and to be more suitable for teacher education. The Triple-A Model includes the essential functions of CBT system. Assembling deals with the construction of item pools, test items, and schedules of tests. Administering is to assign the test items and item choices randomly, provide examination passwords for testees to apply the test through Web as well as collecting and recording the scores data of the tests. Appraising focuses on analyzing the collected/processed data of tests and to generate the statistic report.

Zhenming, et. al. (2003) proposed a web-based operational skills examination and evaluation system for computer courses. In another research work by Rashad, et. al (2010), a web-based online examination system was proposed. The system carries out the examination and auto-grading for student's examinations. The system facilitates conducting examinations, collection of answers, auto marking the submissions and production of reports for the test. It supports many kinds of questions. It was used via Internet and is invariably suitable for both local and remote examination. The system could help lecturers, instructors, teachers and others who are willing to create new examinations or edit existing ones as well as students participating in the examinations. The system was built using various open source technologies. AJAX, PHP, HTML and MYSQL database are used in this system. An auto-grading module was generalized to enable different examination and question types. The system was tested in the Mansoura University Quality Assurance Centre. The test proved the validity of using this kind of web based systems for evaluating students in the institutions with high rate of students. 
e-Examination (Computer-Based Examination)

In many tertiary institutions in Nigeria, the conduct of examinations as well as the process of producing results has been fraught with various problems leading to inability to release results on time, inability of some students to get their results and several incomplete results. These problems can be mitigated using electronic medium.

E-examination, as used in this paper, refers to a system that involves the conduct of examinations through the web or the intranet using the computer system. Recently, because Internet and database technology have been fully developed, CBT which before was once hosted only on personal computers (PCs) or local area networks (LANs), has now gradually been upgraded to work on the Internet using browsers as the test interface so that users can use it anywhere in the world. WES has been seen to be an effective solution for mass education evaluation (Zhenming etal, 2003).

Computer-based examination and test tools have been applied for different purposes, e.g. placement tests, entry-level tests (prognostic tests), self-assessment tests, regular written and oral examinations (selective and diagnostic examinations), and online surveys.

\section{METHODOLOGY AND SYSTEM DESIGN}

This technical paper intends to showcase the development of e-examination application towards enhancing effective distance education where digital divide is eliminated in access to qualitative education across the globe.

The application was developed using different programming models and languages which include HTML, CSS and PHP (for the front-end interface) and MYSQL (for the backend) and served through a web server, APACHE. The use of HTML and CSS, which is a markup language for information presentation and a styling language respectively, allow for the user-interface to be designed and properly laid out. To enable dynamic content generation, PHP (a web scripting language) is used to generate dynamic contents based on the user of the system and the corresponding content stored in the backend database which is managed by MySQL. The web server is used to serve the webpages to users when they are needed, and also to interpret the PHP scripting commands contain in the page. In other words, the computer simply acts as the medium for students to take examinations, for teachers to construct tests, and for the transmission of test papers.

Web-based Examination System Phases

This WES has three phases. Namely: (i) The presentation phase offers an interface to the user. (ii) The business/logic phase serves as the middleware that is responsible for processing the user's requests. (iii) The database phase or question bank serves as the repository of a pool of questions to be answered by the student.

\section{DEVELOPMENT LANGUAGES}

\section{Cascading Style Sheet (CSS)}

It is a set of rules that allow user to control how the web document will appear in the web browser. It defines the formatting applied to a Website, including colors, background images, typefaces (fonts), margins, and indentation. The basic purpose of CSS is to allow the designer to define a style (a list of formatting details such as fonts, sizes, and colors) and then, to apply it to one or more portions of HTML pages using a selector. CSS information can be specified in three different places: (i) within the specific tags in the document body (Inline CSS), (ii) at the top of the document within a <style> block, or combined with named <div> or <span> containers in the document body (Embedded CSS), and (iii) in one or more separate files shared across many Web pages (External CSS) 
Hyper Text Mark-up Language (HTML)

It is the core technology in which all Web pages are written. HTML is not a programming language rather it is a mark-up language for collection of mark-up tags to describe Web pages. Mark-up is made up of tags, and tag names are enclosed in angle brackets.

\section{Hypertext Pre-processor (PHP)}

It is a widely-used Open Source general-purpose scripting language that is specifically suited for Web development and can be embedded into HTML. Unlike other CGI script written in other languages like Perl or $\mathrm{C}$, where lots of commands are written to output HTML, the PHP code is enclosed in special start and end tags that allow you to jump into and out of PHP mode. What distinguishes PHP from something like client-side JavaScript is that the code is executed on the server?

\section{Structured Query Language (SQL)}

This is the standard language designed to access relational databases.

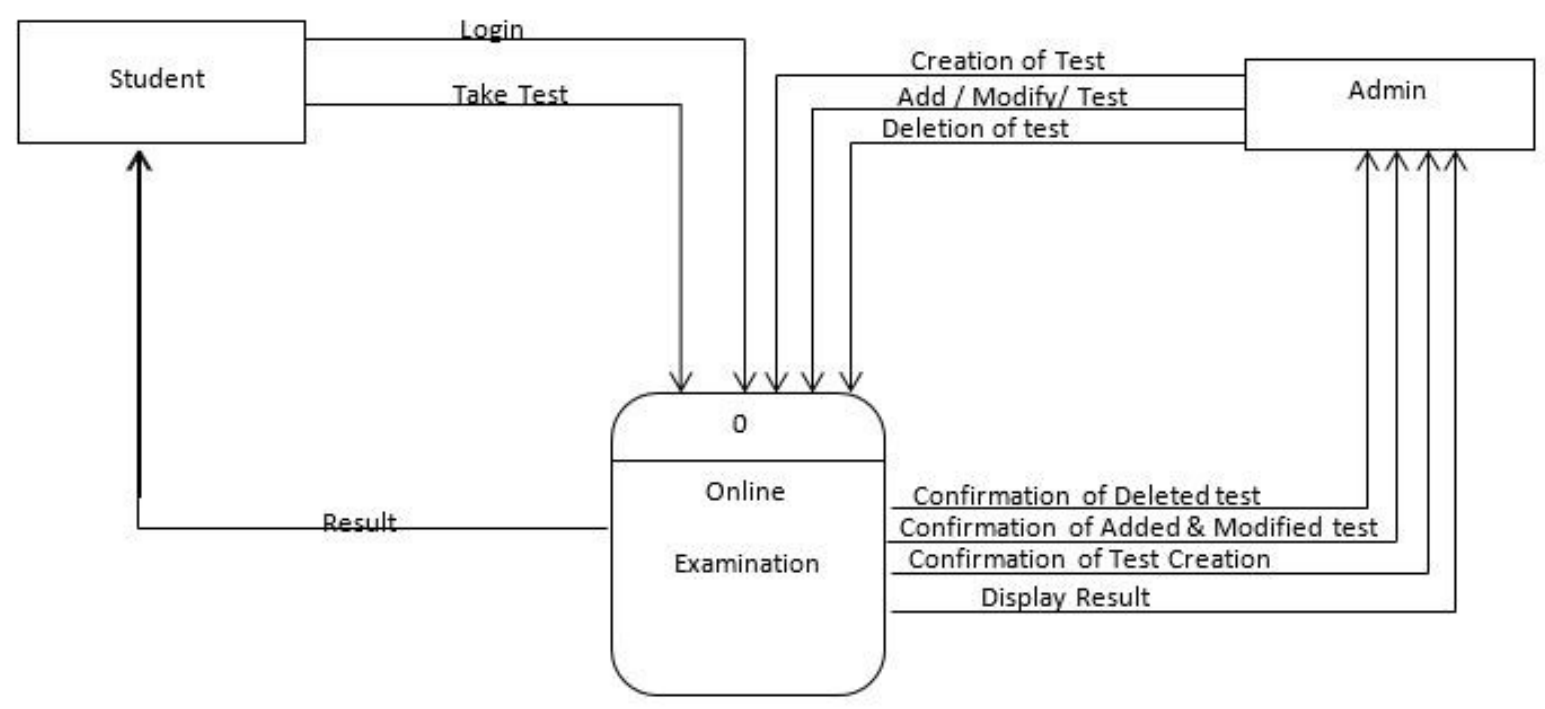

Figure 1: Architecture of the system

To make software development easier and faster, Integrated Development Environment (IDE) may be adopted. An IDE is a software application that provides comprehensive facilities to computer programmers for software development. An IDE normally consist of a source code editor; build automation tools and a debugger (Burd, 2005).

MySQL Workbench

MySQL is the world's most popular open source database, enabling cost effective delivery of reliable, high-performance and scalable web-based and embedded database application. The data in MySQL are stored in tables.

MySQL workbench is a unified visual tool for database architectures, developers, and DBAs. It provides data modeling, SQL development and comprehensive administration tools for server configuration, user administration, backup and much more. MySQL workbench enables a DBA, developer, or data architect to manage databases. It includes everything a data modeler needs for creating complex Entity Relational (ER) models, forward and reverse engineering and also delivers key features for performing difficult change management and documentation tasks that normally require much time and effort. MySQL workbench delivers visual tools for creating, executing and optimizing SQL queries. The SQL editor provides color syntax highlighting, auto-complete, reuse of SQL snippets and execution history of SQL. The database connections panel enables 
developers to easily manage database connections. The object browser provides instant access to database schema and objects.

\section{Dreamweaver CS5}

Dreamweaver is a web design and development application that provides a visual WYSIWYG editor (colloquially referred to as the design view) and a code editor with standard features such as syntax highlighting, code completion and code collapsing as well as more sophisticated features such as real-time syntax checking and code introspect for generating code hints to assist the user in writing code. The design view facilitates rapid layout design and code generation as it allows users to quickly create and manipulate the layout of HTML elements. It also features an integrated browser for previewing developed webpages in the program's own preview pane in addition to allowing content to be open in locally installed web browsers. Dreamweaver provides transfer and synchronization features, the ability to find and replace lines of text or code by search terms or regular expressions across the entire site, and a templating feature that allows single-source update of shared code and layout across entire sites without server-side includes or scripting. Dreamweaver like other HTML editors, edit files locally then uploads them to the remote web server using FTP, SFTP or WebDAV.

\section{SYSTEM DESIGN}

\section{Database (Backend) Design}

Database design is concerned with how data is represented and stored within the system. The examination questions, answers, grades, and reviews must be stored in a persistent way. Moreover, we need to keep information about the students. The system stores the above information in a MySQL Database server. Such database has been chosen since it is open source, and there are implementations available for the main architectures

\section{User Interface (Frontend) Design}

Usability is the ease with which a user can learn to operate, prepare inputs for, and interpret outputs of system or component. This usability of a system is made less more or less stressful by the usability and complexity of the user interface. The user interface of a system is therefore the part of the system that the end user interacts with. User interface design is concerned with how users add information to the system and with how the system presents information back to them.

\section{Bootstrap}

Bootstrap is a collection of tools for creating websites and web applications. It contains HTML and CSS-based design templates for typography, forms, buttons, navigation and other interface components as well as optional JavaScript extensions. Bootstrap was developed at Twitter as a framework to encourage consistency across internal tools. Bootstrap is compatible with all major browsers and it also supports responsive design i.e. the layout of web pages adjusts dynamically, taking into account the characteristics of the device used (PC, tablet, mobile phone). Bootstrap works by proving a clean and uniform solution to the most common, everyday interface tasks developers come across. It is flexible enough to work for many unique design needs.

\section{SYSTEM REQUIREMENTS AND SPECIFICATIONS}

\section{Functional Requirements}

Functional requirement defines the capabilities and functions that a system must be able to perform successfully. In software engineering and system engineering a functional requirement defines a function of a system or its component. These functions are the set of inputs, the behavior and outputs of the system in question. In order words it captures the intended behavior of the system. This behavior may be expressed as services, tasks or functions the system is required to perform and it shows the features that differentiate the system from other systems. Functional requirements should include: Descriptions of data to be entered into the system, descriptions of operations performed by each screen, 
descriptions of work-flows performed by the system, which can enter the data into the system and how the system meets applicable regulatory requirements

The intended software's functions are highlighted below:

$>\quad$ The system has a homepage where respective users (administrator \& students) can login to perform their different operations.

$>$ The system has the test page where the student would be presented with test questions to be answered by him/her. The system then automatically adds the marks allocated in each question to determine the total mark for the test.

\section{Non-functional Requirements}

These define system properties and constraints e.g. reliability, response time and storage requirements. Constraints are $\mathrm{I} / \mathrm{O}$ device capability, system representations, etc. It is a requirement that specifies criteria that can be used to judge the operation of a system, rather than specific behaviors. This should be contrasted with functional requirements that define specific behavior or function.

\section{SYSTEM IMPLEMENTATION}

To test the effectiveness of the design, PHP and HTML were used, with MySQL as the back-end integration database. The choice of these programming languages is based on the features of the languages that make them very appropriate for this work.

\section{System Requirement and Specification}

The minimum hardware and software requirements for the WES are: Minimum of Pentium IV or IBM compatible system, $500 \mathrm{Mhz}$ processor speed or higher, minimum of $512 \mathrm{MB}$ memory capacity, minimum of Windows XP as the operating system (OS), support any web browser. Internet Explorer, Mozilla Firefox, Google Chrome and Xamp server.

\section{Interfaces}

\section{Login/register page}

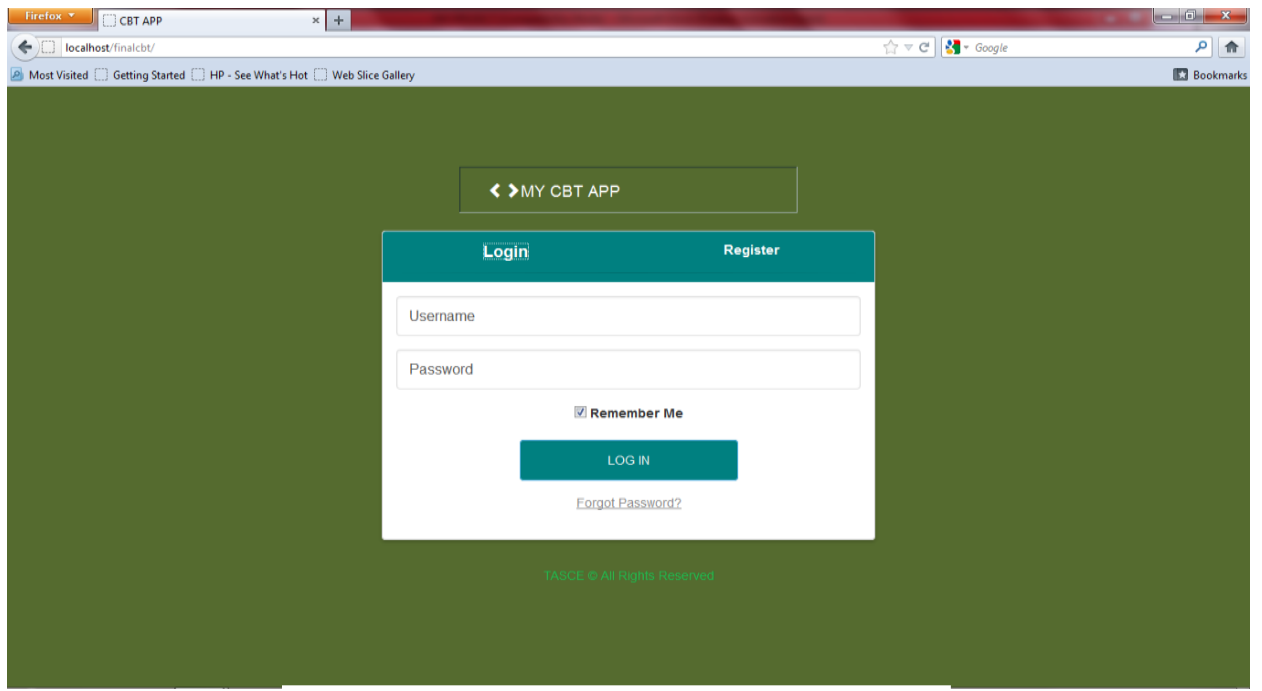

Figure 2. Log-in Page

Login module helps the user (students or lecturers) to login to the site. The lecturer cannot login on this platform but would be done by the administrator. An administrator is to register the lecturers' credential and then provide each lecturer with login credentials. The students must register first before using the registered credentials to login. The login provision in this page helps the already registered user to directly access the site. On the page spaces have been provided for the user (students) to enter their respective username and password. 


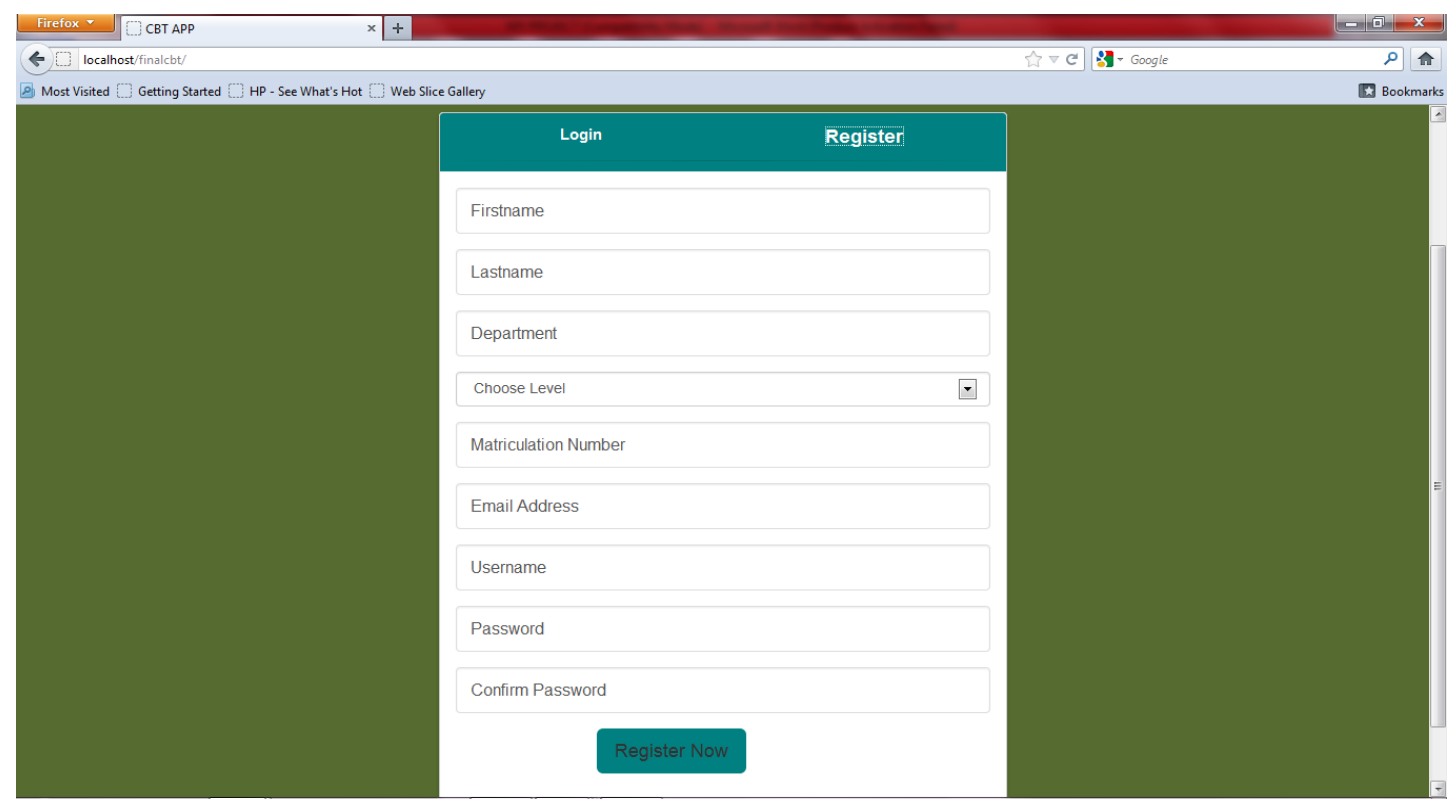

Figure 3. Register Page

Lecturer's examination creation page

This platform enables the lecturer to set examination mode before proceeding to set the questions. Here, course name and code will be specified by the lecturer including the allocated time and date of the examination.

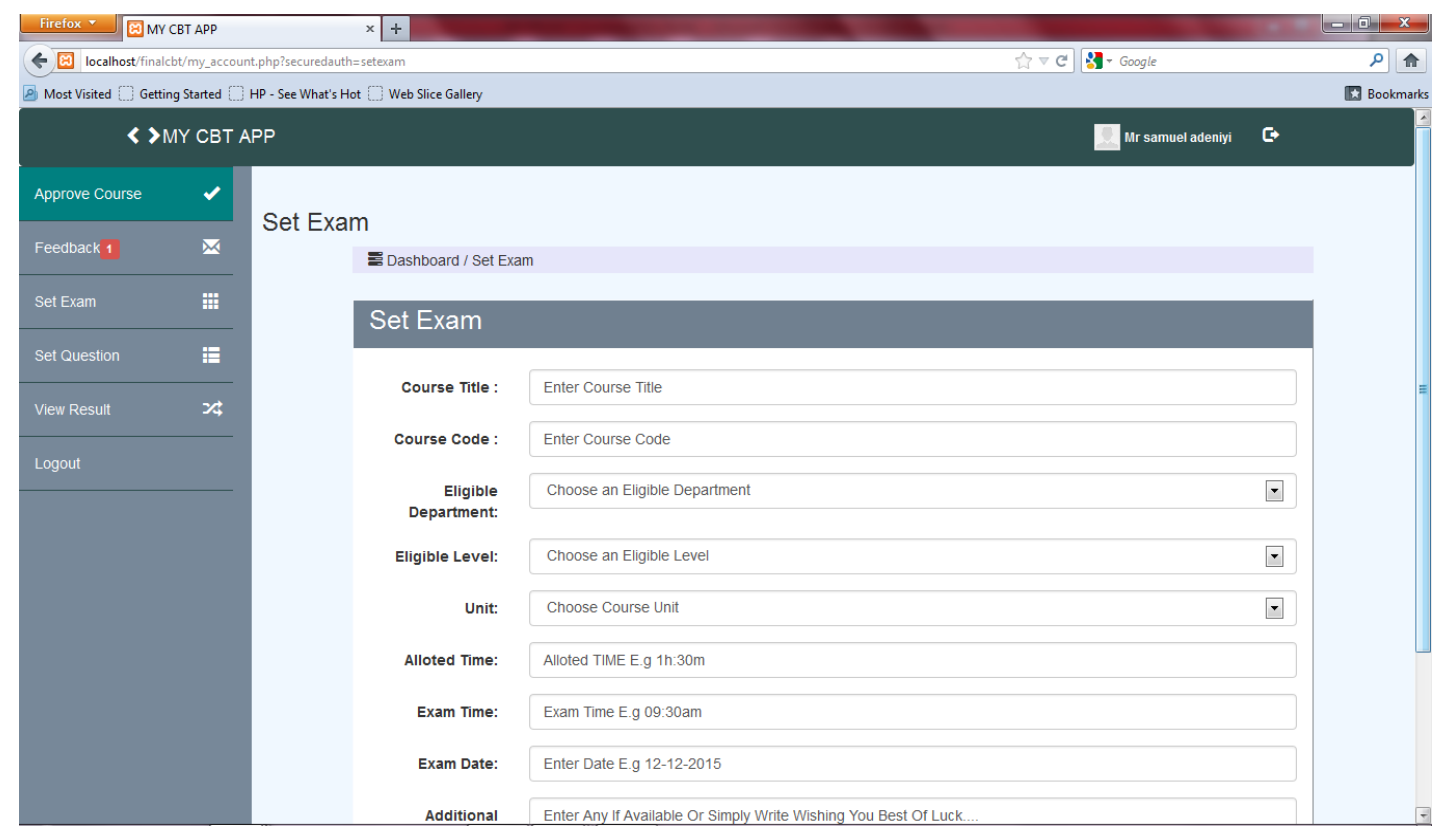

Figure 4. Examination Setup Page

Question, examination and result pages

After setting up the examination, the lecturer will proceed in setting up the questions for the examination. This platform will provide the avenue for questions setup and correct answer to each question will be marked by the lecturer. 


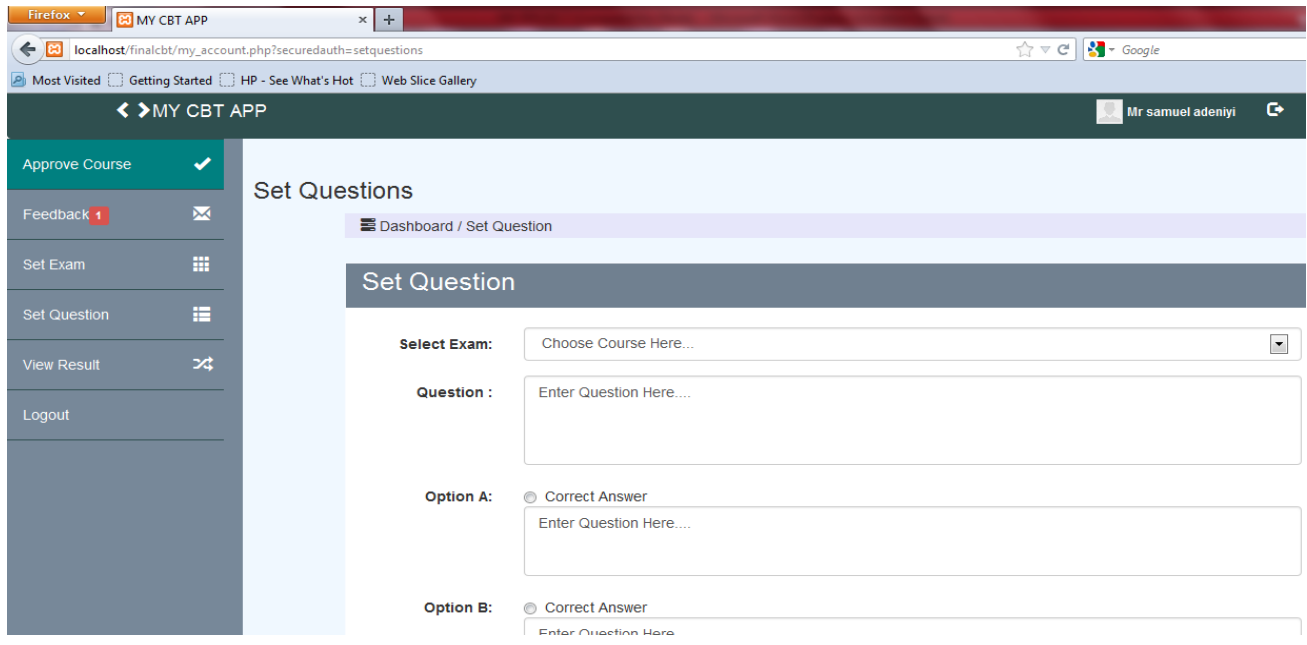

Fiaure 5. Ouestion Creation

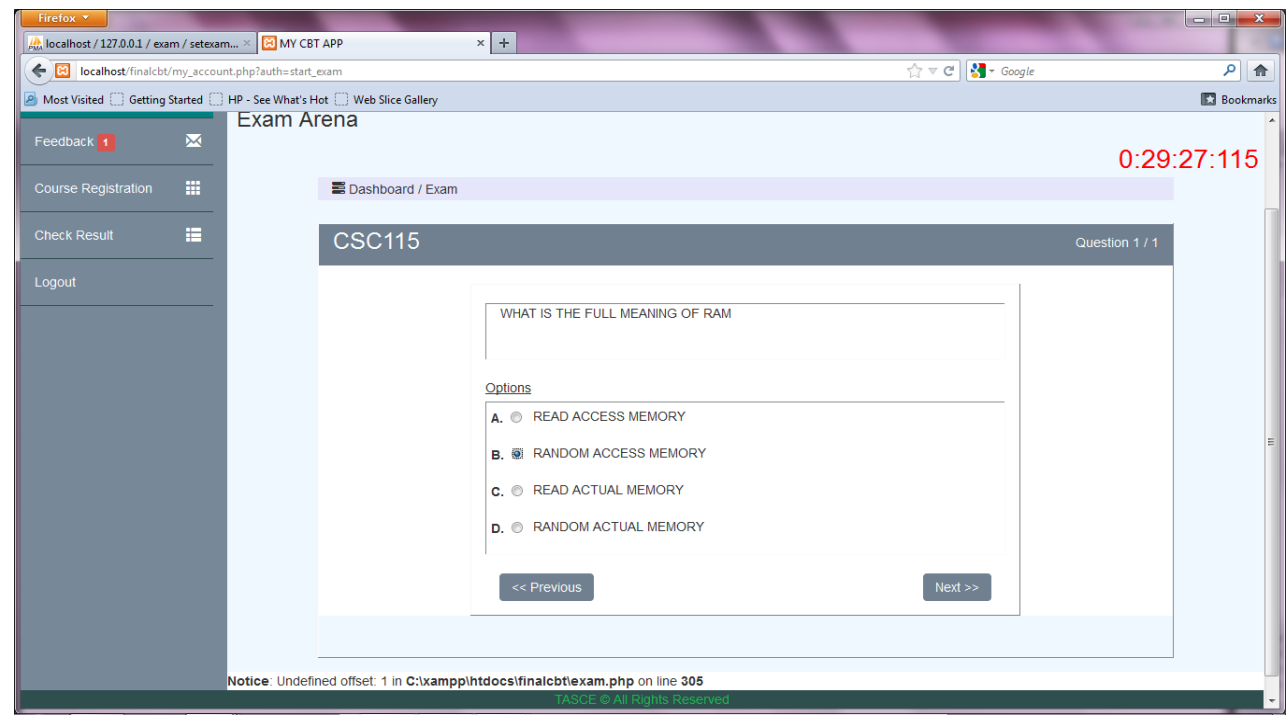

Figure 6. Examination Page

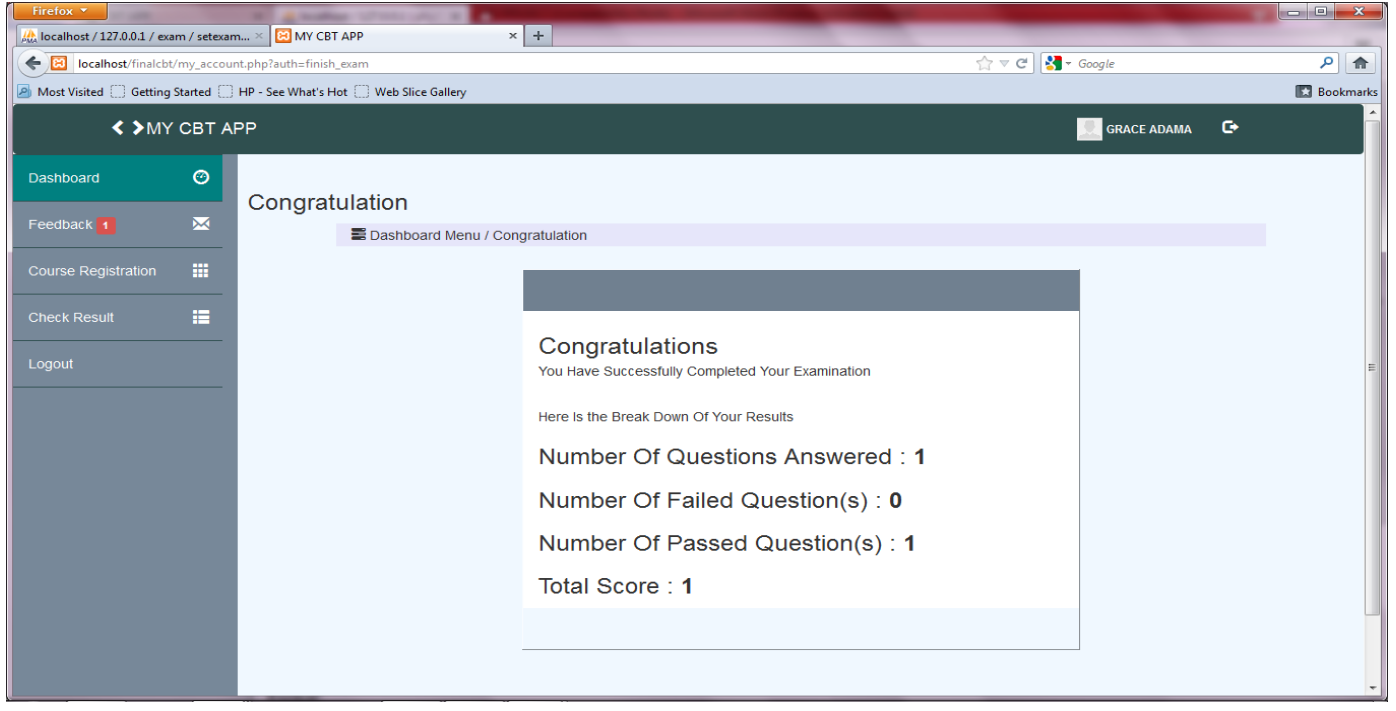

Figure 7. Examination Completion Page 


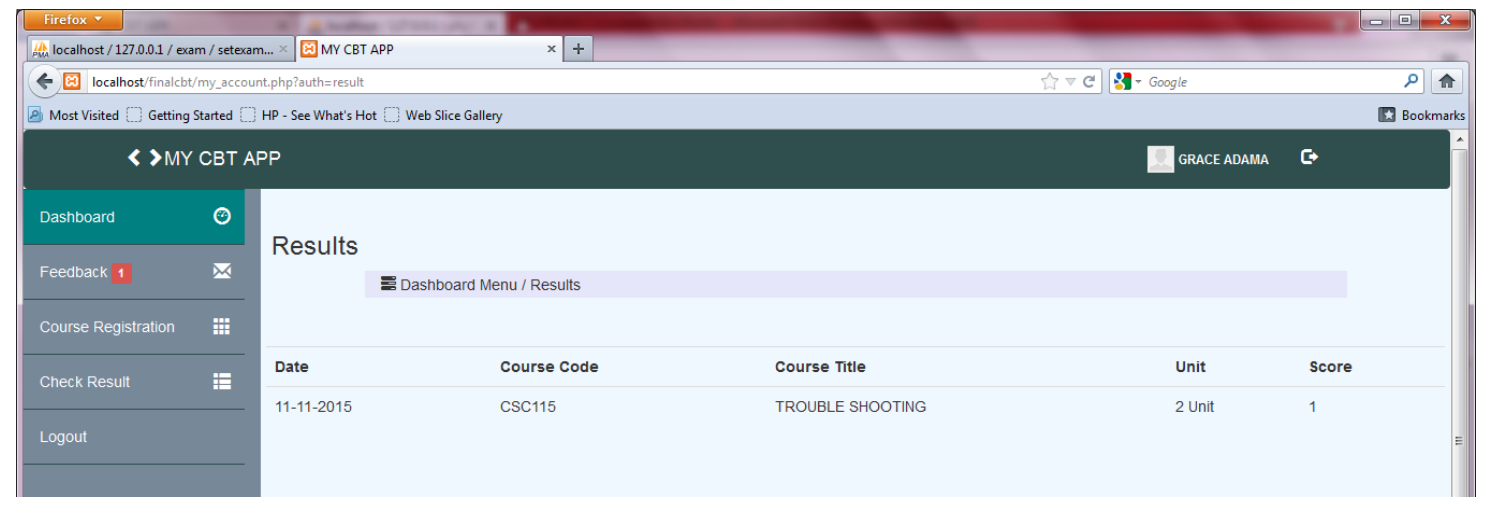

Figure 8. Result Page

Backend/Database Design

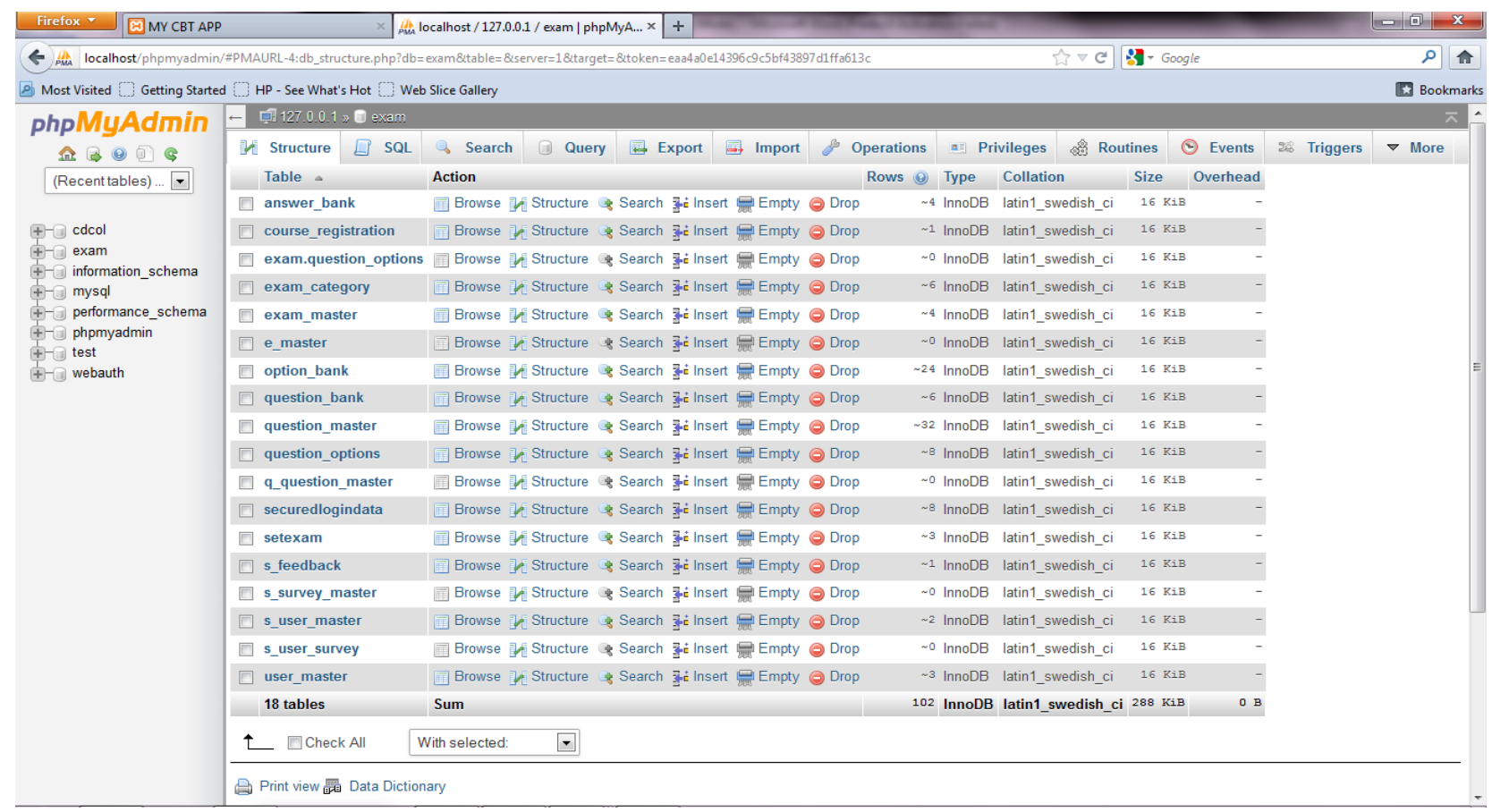

Figure 9. Database View Page

Database design is the process of producing a detailed data model of a database. This logical data model contains all the needed logical and physical design choices and physical storage parameters needed to generate a design in a Data Definition Language, which can then be used to create a database. The database of the system is presented below. The database has eight tables (admin, courses, option, question, registration, results, student, and tests) in it. The option table holds the various options to the questions to be presented to the students, the results table holds the various scores of the students that partook in the test, the question table holds the questions that would be presented to the students, while the students table holds the students' information.

\section{CONCLUSION AND RECOMMENDATIONS}

It is not enough to focus on the passing required skills to the learners in distance education but to equally furnish them with their performances shortly after evaluation without hitch. Consequently, the developed WES is capable of solving the associated problems with the traditional test methods and equally promotes distance education. 
When online method of instruction is used to acquire skills in higher education, the application can be used for efficient assessments regardless of the location of the examinees across the globe.

It is possible with this system to space the period of examination without compromising quality and integrity of the examination. The system has the potentials to reduce drastically examination malpractice as applicants are duly authenticated online, real-time before taking the examination and the integrity of the result could also be enhanced since the candidates have access to instant result checking.

Hence, in the current era of distance education prompted by the adoption of ICT, the eExamination has the advantage of being easy to administer, ability to offer applicants instant results, easy verification, devoid of paper work and long-time involved in marking examination scripts which in most cases are prone to errors and misplacement of some scripts due to the large volume of scripts that has to be marked and accessed. The system also saves the instructors from sufferings and boring grading of works as well as examinees' access to results thereby promoting efficient distance education system.

If the e-examination system is fully optimized and it is introduced into the institutions, it will go a long way to control and check examination malpractices and all fraudulent acts associated with the manual process of writing examination. However, for the system to be adopted on a large scale, efforts should be intensified to ascertain its disadvantage on accounts of IT illiteracy on the part of the students', by making the interface easy to interact with. Also, to ensure that the e-examination system is not intensified by those that may want to engage in any form of examination malpractice, the addition of user authenticated protocol/methods such as biometrics (fingerprint, retina, iris etc) identification will be of good help.

In future, we intend to address the limitations of the current application by incorporating online collation of results from various courses examined, compute Cumulative Grade Point Aggregate (CGPA) and generation of transcripts (with necessary security features) to foster implementation of distance education.

\section{BIODATA and CONTACT ADDRESSES of AUTHORS}

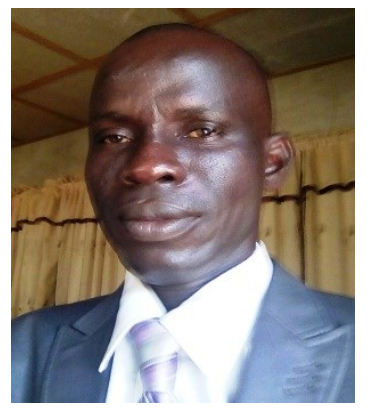

Olalere A. ABASS is a lecturer in the Department of Computer Science, School of Science, Tai Solarin College of Education, OmuIjebu, Ogun State, Nigeria. He obtained M.Sc. Computer Science from University of Ibadan, Nigeria in 2012 and currently a Ph.D. student in the Department of Computer Science, Federal University of Agriculture, Abeokuta, Nigeria. His academic interest areas are information systems, database management, web application development and e-learning implementation. He has over 13-year experience in research and teaching with 14 publications in both national and international journals.

Olalere A. ABASS

Department of Computer Science,

Tai Solarin College of Education, Omu-Ijebu, 120103, Ogun State, Nigeria.

Phone: +234-818-167-5151,

E-mail: olaabas@gmail.com 


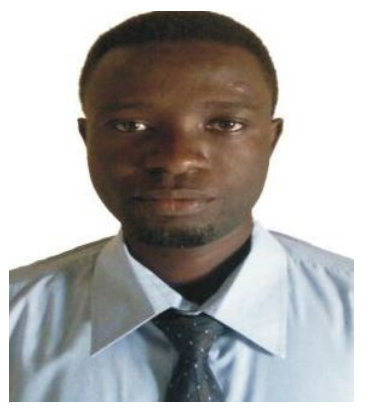

Samuel A. OLAJIDE studied Computer Science/Mathematics in the Department of Computer Science, School of Science, Tai Solarin College of Education, Omu-Ijebu, Ogun State, Nigeria. He obtained his National Certificate in Education in $\mathbf{2 0 1 5}$ from this institution. He is currently a research student in Computer Science with Education in the Department of Educational Technology, Faculty of Education, University of Ilorin, Nigeria. His academic interest area is web application development.

Samuel A. OLAJIDE

Department of Educational Technology (Computer Science Option), University of Ilorin, Ilorin, 240003, Nigeria.

Phone: +234-706-235-2644

E-mail: samolatec@gmail.com

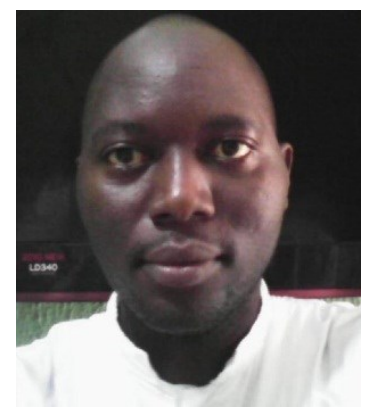

Babafemi O. SAMUEL is a lecturer in the Department of Computer Science, School of Science, Tai Solarin College of Education, OmuIjebu, Ogun State, Nigeria. He obtained B.Sc.(Ed.) Computer Science from Tai Solarin University of Education, Ijagun, Nigeria. He is currently a postgraduate student of Computer Science in National Open University of Nigeria, Abuja, Nigeria. He has 5 years of teaching and research. His academic interest areas web application programming and database administration. He has both national and international journals to his credit.

Babafemi O. SAMUEL

Department of Computer Science,

Tai Solarin College of Education, Omu-Ijebu, 120103, Ogun State, Nigeria.

Phone: +234-806-534-9798

E-mail: princefm@live.com

\section{REFERENCES}

Akanbi, C.O., \& Adetunji, A.B (2012). An Online Essay-Based ExaminationAssessment Model Using Double Blind Marking Tecnique. African Journal of Computing and ICT, 5(6), 104-108.

Ayo, C., Akinyemi, I., Adebiyi, A., \& Ekong, U. (2007). The Prospects of E-Examination. Turkish Online Journal of Distance Education-TOJDE, 8(4), 125-134

Burd, B. (2005). Beginning Programming with Java for Dummies, 2nd ed. Indianapolis, Indiana: Wiley Publishing, Inc.Indianapolis, Indiana.

Chen, D.J., Lai, A.F., \& Liu, I.C. (2005). The Design and Implementation of a Diagnostic Test. Journal of Information Science and Engineering, 21, 1007-1030.

Gardner, L., Sheridan, D., \& White, D. (2002). A Web-based learning and assessment system to support flexible education. Journal of Computer Assisted Learning, 18, 125-136.

Iyilade, J. S., \& Odekunle, W. O. (2005). A Web-based Student Testing and Assessment System. Teaching, Research and Administration, AICTTRA, 1, 16-24. 
Olga D. R. (2004). Multilingual Graphical Authoring Editor in a Distributed e-Testing Cluster. Proceeding of Electronics' 2004, Sozopol, Bulgaria.

Rashad, M. Z., Mahmoud S, K., Ahmed E, H., \& Mahmoud A, Z. (2010). An Arabic WebBased Examination. International Journal of Electrical \& Computer Sciences, 10(1), 48-54.

Wang, T. H., Wangw, K. H., W. L. Wangz, Huangz, S. C., \& Chen, S. Y. (2004). Web-based Assessment and Test Analyses (WATA). Journal of Computer Assisted Learning, 20, 59-71.

Zhaozong Meng \& Joan Lu (2011). Implementing the Emerging Mobile Technology in Facilitating Mobile Exam System. Proceedings of 2nd International Conference on Networking and Information Technology, Singapore.

Zhenming, Y., Zhang, Z., \& Zhan, L. (2003). A novel web-based examination system for computer science education. 33rd ASEE/IEEE Frontiers in Education Conference, S3F-7 - S3F-10, 2003 